\title{
Microstructure and Mechanical Properties of CNT-Reinforced AZ91D Composites Fabricated by Ultrasonic Processing
}

\author{
Fu-Ze Zhao ${ }^{1}$ Xiao-Hui Feng ${ }^{1} \cdot$ Yuan-Sheng Yang ${ }^{1}$
}

Received: 23 March 2016/Revised: 14 April 2016/Published online: 3 June 2016

(c) The Chinese Society for Metals and Springer-Verlag Berlin Heidelberg 2016

\begin{abstract}
Carbon nanotube (CNT)-reinforced AZ91D alloy composite was fabricated by ultrasonic processing. The microstructure and mechanical properties of the CNTs/AZ91D composites were investigated. Obvious grain refinement was achieved with the addition of $0.5 \mathrm{wt} \%$ CNTs. The SEM observation indicated that CNTs were distributed near the grain boundary or around the inter-grain $\beta-\mathrm{Mg}_{17} \mathrm{Al}_{12}$ phase. No evident reaction product was found at the interface between CNTs and AZ91D matrix. Compared to the monolithic AZ91D alloy, the yield strength, ultimate tensile strength, and elongation of the $0.5 \mathrm{wt} \% \mathrm{CNTs} / \mathrm{AZ} 91 \mathrm{D}$ composite were improved significantly. However, the poor interface bonding between CNTs and AZ91D matrix restricted further improvement in mechanical properties.
\end{abstract}

KEY WORDS: Carbon nanotubes (CNTs); Magnesium matrix composites; Ultrasonic vibration; Microstructure; Mechanical properties

\section{Introduction}

Magnesium matrix composites have attracted much attention due to their improved physical and mechanical properties over monolithic magnesium. Among these magnesium matrix composites, particulate-reinforced composites are becoming more popular due to their lower reinforcement costs and easier fabrication processes. Mechanical properties of magnesium such as hardness, modulus, and tensile strength can be significantly improved by using micrometer-size particles as reinforcement [1-6]. However, low ductility is a big problem for this kind of materials $[1,2,5]$. For further improvement or at least no significant reduction in ductility, nanometer-size

Available online at http://link.springer.com/journal/40195

Yuan-Sheng Yang ysyang@imr.ac.cn

1 Institute of Metal Research, Chinese Academy of Sciences, 72 Wenhua Road, Shenyang 110016, China reinforcements are introduced [7, 8]. Among these nanometer-size reinforcements, carbon nanotubes (CNTs) are good candidates due to their high stiffness, strength, Young's modulus, and low density [9].

Achieving a homogeneous distribution of reinforcements is the critical issue for nanosize particles reinforced magnesium composites [10]. And due to the large lengthdiameter ratio of CNTs, it is hard to obtain homogeneously dispersed CNT-reinforced magnesium composites by general dispersion methods such as mechanical stirring. Powder metallurgy (PM) method is an effective candidate to fabricate CNT-reinforced magnesium composites because dispersion difficulties can be overcome through its mixing process such as ball-milling. But the high chemical reactivity of $\mathrm{Mg}$ means $\mathrm{MgO}$ is easy to form and finally deteriorate the ductility. Shimizu et al. [11] used ballmilling process plus hot-pressing to mix and composite short CNTs and AZ91D powders. The results showed that the $0.2 \%$ proof tensile strength and elastic modulus were improved, but the ductility was significantly decreased. Kondoh et al. [12] used a wet process to disperse CNTs onto the surface of magnesium powders and AZ31B 
powders and finally improved the strength but deteriorated the ductility. Based on Kondoh's research, Fukuda et al. [13] changed the solvent used in the wet process from water to isopropyl alcohol and the ductility decrease was only relatively reduced. Another method to fabricate CNTs reinforced magnesium composite is disintegrated melt deposition (DMD) method and was used by Gupta's group to fabricate CNTs/Mg [14] and CNTs/AZ81 [15] composites. An important finding in their studies is that CNTs improves the ductility of magnesium and magnesium alloy as well as their strength. Ultrasonic processing is also an effective way to fabricate CNTs reinforced magnesium composite because CNTs can be well dispersed in the magnesium melt by ultrasonic melt treatment. Liu et al. [16] fabricated CNTs/AZ91D composite successfully by using ultrasonic processing. Li et al. [17, 18] fabricated CNTs/Mg6Zn composite through an ultrasonic processing that consists of pre-dispersion, semisolid stirring, and ultrasonic melt treatment, and both the strength and ductility were improved when 0.5 vol\% CNTs were added in. Shi et al. [19] fabricated CNTs/Mg6Zn composite by using a novel method consisted of ball-milling and ultrasonic melt processing.

Although several different kinds of Al-containing magnesium alloy such as AZ31B [12], AZ81 [15], AZ91D $[11,16]$ have been used as matrix for CNTs reinforced magnesium composites, there is still a concern whether the Al element in magnesium alloy would react with CNTs and destroy their structure especially when ultrasonic processing is used since the fabrication temperature is above the melt point. Ci et al. [20] investigated the interface reaction between multi-walled CNTs and pure Al. They found that the cylindrical structure of the CNTs with high graphitization is inert to the reaction with liquid $\mathrm{Al}$ even at high temperatures (above the Al melting point) and the reaction occurs at the amorphous carbon coating, possible defects along the nanotubes and the opened nanotube ends. According to their results, less than $10 \mathrm{wt} \% \mathrm{Al}$ element in magnesium alloy seems unable to induce a degradation of CNT. But considering that the wettability improved by ultrasonic melt treatment, the reaction between $\mathrm{Al}$ and CNTs may happen. So it is still important to investigate whether the reaction between $\mathrm{Al}$ and CNTs happens in the CNT-reinforced Al-containing magnesium alloy composites fabricated by ultrasonic processing. And the influence of CNTs on the microstructure and mechanical properties of Al-containing magnesium alloy composites also needs to be further studied.

Accordingly, in this work, commercial AZ91D containing $9 \mathrm{wt} \% \mathrm{Al}$ was chosen as matrix material. Ultrasonic processing containing pre-dispersion process, semisolid stirring, and ultrasonic melt treatment was used to fabricate CNTs/AZ91D composites. The interface between CNTs and the matrix was studied. The influence of CNTs on microstructure and mechanical properties of AZ91D alloy was also investigated. And whether AZ91D magnesium alloy is suitable for matrix for CNTs was analyzed.

\section{Materials and Methods}

The chemical composition of the commercial AZ91D used in this work is listed in Table 1. The CNTs synthesized using CVD method by Chengdu Organic Chemistry Co. Ltd., China, had an external diameter of 10-30 nm and a length of $20 \mu \mathrm{m}$, as shown in Fig. 1a, b.

The chemical dispersant TNADIS (Chengdu Organic Chemistry Co. Ltd., China) was first dissolved in ethyl alcohol in a small beaker. Then CNTs were added in and an ultrasonic bath was used in order to obtain a homogeneous mixture. The ultrasonic time was about 1 or $2 \mathrm{~h}$ decided by the uniformity. After adding AZ91D chips (length: 2-6 mm, width: $5 \mathrm{~mm}$, thickness: $0.5 \mathrm{~mm}$ ), 30-min ultrasonic bath was used for further degassing. Then the mixture was stirred for $10 \mathrm{~min}$ at $250 \mathrm{r} / \mathrm{min}$. Finally, the beaker was transferred to a drying oven at $70{ }^{\circ} \mathrm{C}$ to evaporate ethanol. The ratio of CNTs, dispersant, AZ91D chips, and ethanol is $1 \mathrm{~g}: 0.15 \mathrm{~g}: 10 \mathrm{~g}: 30 \mathrm{~mL}$. Figure 1c, d shows the surface of the final AZ91D chips covered with CNTs.

About $665 \mathrm{~g}$ AZ91D ingot was melted at $690{ }^{\circ} \mathrm{C}$ in a steel crucible with $70 \mathrm{~mm}$ in inner diameter under $\mathrm{CO}_{2}+\mathrm{SF}_{6}$ atmosphere. Then the melt was cooled down to $590{ }^{\circ} \mathrm{C}$ at which temperature AZ91D was in semisolid state. After $35 \mathrm{~g}$ AZ91D chips covered with CNTs (0.5 wt $\%$ CNTs) was added in, the melt was stirred for $8 \mathrm{~min}$ at $600 \mathrm{r} / \mathrm{min}$. Then the mixture was heated to $670{ }^{\circ} \mathrm{C}$, and a cylindrical ultrasonic probe with $30 \mathrm{~mm}$ in diameter was immersed in. After 10-min preheating, a 20-kHz, 1-kW high-intensity ultrasonic wave was introduced through the probe. The ultrasonic melt treatment proceeded for $20 \mathrm{~min}$ and the immerse depth of probe was $30 \mathrm{~mm}$. When the ultrasonic melt treatment was over, the ultrasonic probe was removed immediately and the melt was rapidly cast into a steel mold (preheated to $250{ }^{\circ} \mathrm{C}$ ). For comparison, two kinds of AZ91D comparison samples were also made. Type A means the AZ91D samples without CNTs and fabricated without ultrasonic melt treatment; Type B means the AZ91D samples without CNTs and fabricated with ultrasonic treatment.

Table 1 Chemical composition of the commercial AZ91D (in wt\%)

\begin{tabular}{lllllllll}
\hline $\mathrm{Al}$ & $\mathrm{Zn}$ & $\mathrm{Mn}$ & $\mathrm{Be}$ & $\mathrm{Fe}$ & $\mathrm{Cu}$ & $\mathrm{Si}$ & $\mathrm{Ni}$ & $\mathrm{Mg}$ \\
\hline 8.89 & 0.62 & 0.32 & 0.0011 & 0.0017 & 0.0067 & 0.044 & 0.0005 & Bal.
\end{tabular}



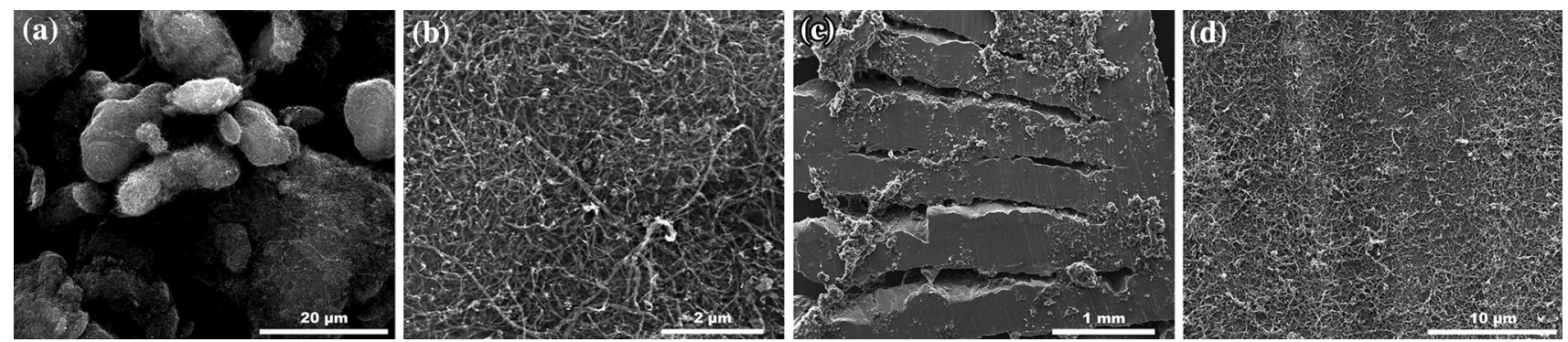

Fig. 1 SEM images of the raw CNTs a, $\mathbf{b}$ and AZ91D chips covered with CNTs $\mathbf{c}, \mathbf{d}$

An optical microscope (OM, Zeiss Axio Observer $\mathrm{Z1m}$ ) was used to observe the grain size of both the monolithic AZ91D and CNTs/AZ91D composite and Jeffries' procedure was used to measure the grain size. The microstructure and distribution of CNTs were investigated with a scanning electron microscope (SEM, FEI Inspect F50) equipped with an EDS detector. The phase analysis was carried out using X-ray diffraction (Rigaku D/max 2500 PC). A transmission electron microscopy (TEM, Tecnai F30) was used to observe the interface between CNTs and the matrix. The specimens for grain size measurement were firstly heat treated at $415{ }^{\circ} \mathrm{C}$ for $20 \mathrm{~h}$ (for the convenience to show the grain) and then prepared by conventional mechanical grinding, polishing, and etched at room temperature for $40 \mathrm{~s}$ using a solution of $1 \mathrm{~mL}$ glacial acetic acid, $0.5 \mathrm{~mL}$ nitric acid, $75 \mathrm{~mL}$ ethanol, and $25 \mathrm{~mL}$ distilled water. For SEM observation, no heat treatment was used and the specimens were etched for $10 \mathrm{~s}$ using $4 \%$ nitric acid. Specimens for TEM tests were prepared by mechanical grinding, cutting, dimple grinding, and ion-beam thinning (from $5 \mathrm{kV}, 6^{\circ}$ to $1 \mathrm{kV}$, $3^{\circ}$ ), and no water was used during the preparation. Tensile tests were carried out on an Instron Series 5582 test machine at room temperature with crosshead speed of $1 \mathrm{~mm} / \mathrm{min}$ (ASTM B557, four $5 \mathrm{~mm} \times 25 \mathrm{~mm}$ samples for each type). The tensile facture surfaces were observed by SEM (FEI Inspect F50).

\section{Results}

\subsection{Grain Size}

Figure 2 shows the optical micrographs of AZ91D alloys and CNTs/AZ91D composite. The grain size (average grain diameter) of monolithic AZ91D without ultrasonic process (AZ91D Type A) was $180 \mu \mathrm{m}$ (Fig. 2a), while the grain size of monolithic AZ91D with ultrasonic process (AZ91D Type B) was $125 \mu \mathrm{m}$. When CNTs were added in, the grain size decreased to $70 \mu \mathrm{m}$ (Fig. 2c).

\subsection{Phase Component}

As shown in Fig. 3c, the matrix of CNTs/AZ91D composite consisted of three phases: $\alpha-\mathrm{Mg}$ (black), $\beta-\mathrm{Mg}_{17} \mathrm{Al}_{12}$ (gray, massive and lamellar), and a few $\mathrm{Al}_{8} \mathrm{Mn}_{5}$ phase (white), which can be demonstrated by the EDS results (Fig. 4). This phase component and distribution had no obvious difference with monolithic AZ91D (Fig. 3a, b). An observable change happened to the morphology of $\mathrm{Al}_{8} \mathrm{Mn}_{5}$ phase, from dendritic (Fig. 3a) to small spherical (Fig. 3c), but this change did not caused by the addition of CNTs because it also could be seen in AZ91D sample with ultrasonic melt treatment (AZ91D Type B, Fig. 3b). More than ten SEM images of each sample were measured and the area fractions of each phase are shown in Table 2. The application of ultrasonic and the addition of CNTs caused no obvious changes to phase fractions. And due to the trace amounts of $\mathrm{Al}_{8} \mathrm{Mn}_{5}$ phase, the XRD analysis results (Fig. 3d) show no other peak but $\mathrm{Mg}$ and $\mathrm{Mg}_{17} \mathrm{Al}_{12}$ peaks.

\subsection{Distribution of CNTs}

Figure 5 shows the distribution of CNTs in AZ91D matrix. Most CNTs are located near the eutectic phase at the grain boundary (Fig. 5a) or around the small intra-crystalline $\beta-\mathrm{Mg}_{17} \mathrm{Al}_{12}$ phase (Fig. 5b).

\subsection{Interface between CNTs and Matrix}

Figure 6 shows the interface of CNTs and the $\alpha-M g$ matrix. Figure 6a shows the HAADF-STEM image of the interface between a CNT and matrix. During the preparation process of the TEM foil, this CNT was slit and separated from the matrix. A clear separation line is shown in Fig. 6a. No obvious interfacial reaction product was found either at this CNT surface or at the separation surface of $\alpha-\mathrm{Mg}$ matrix. The HRTEM image (Fig. 6b) had a higher resolution ratio, and the interfacial reaction product was still not found. It was indicated that the reaction between CNTs and $\mathrm{Al}$ element in AZ91D alloy did not happen or at least was not 

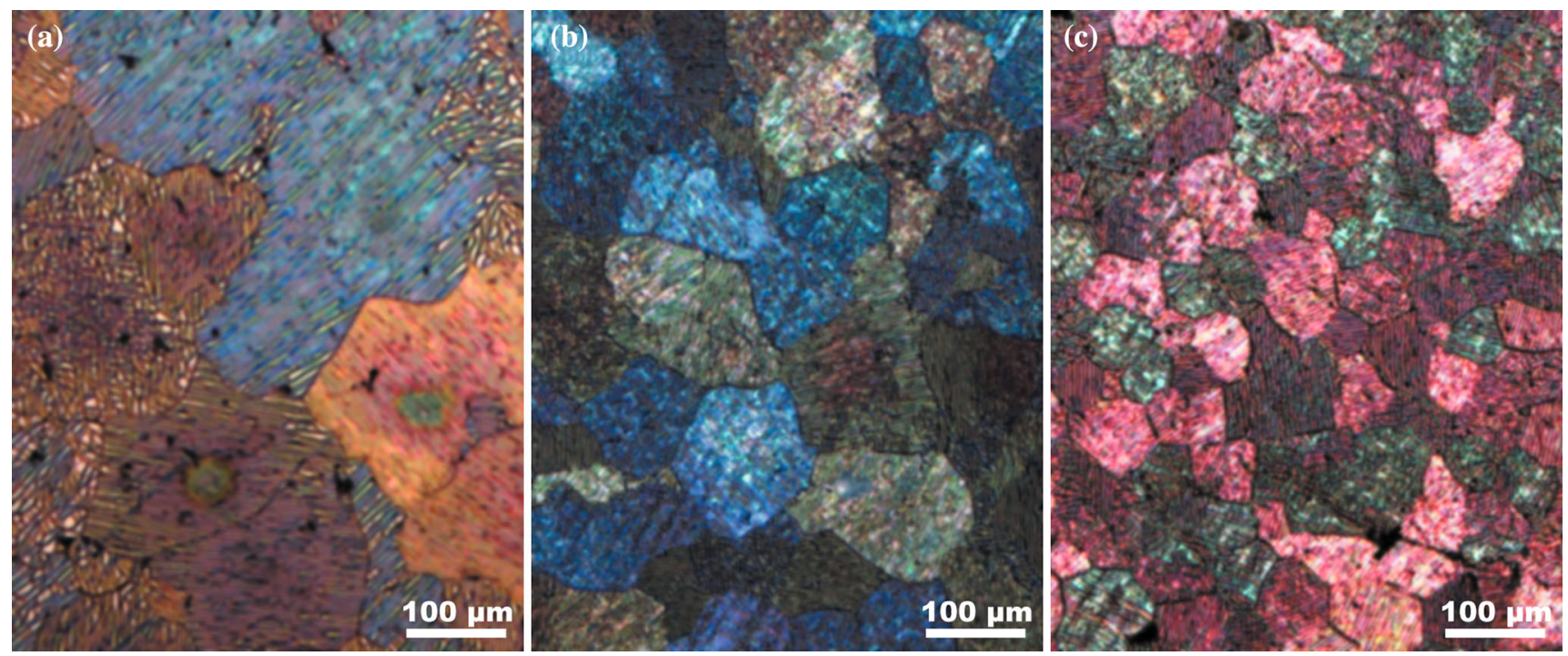

Fig. 2 Optical micrographs of AZ91D and CNTs/AZ91D composite using polarized light: a AZ91D Type A; b AZ91D Type B; c 0.5 wt\% CNTs/AZ91D composite
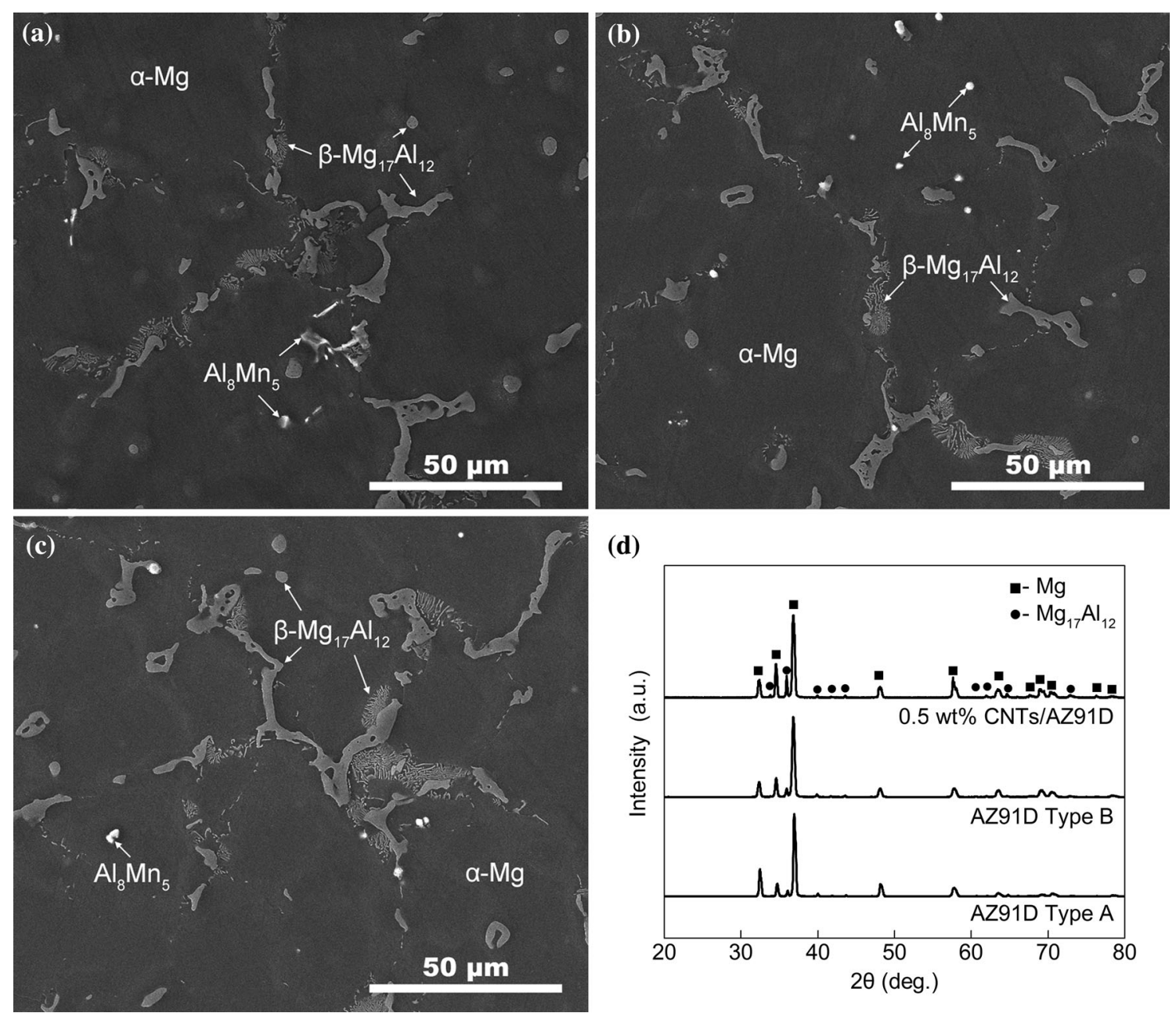

Fig. 3 SEM images of AZ91D Type A a, AZ91D Type B b, CNTs/AZ91D composite $\mathbf{c}$ and the XRD patterns of these samples d 


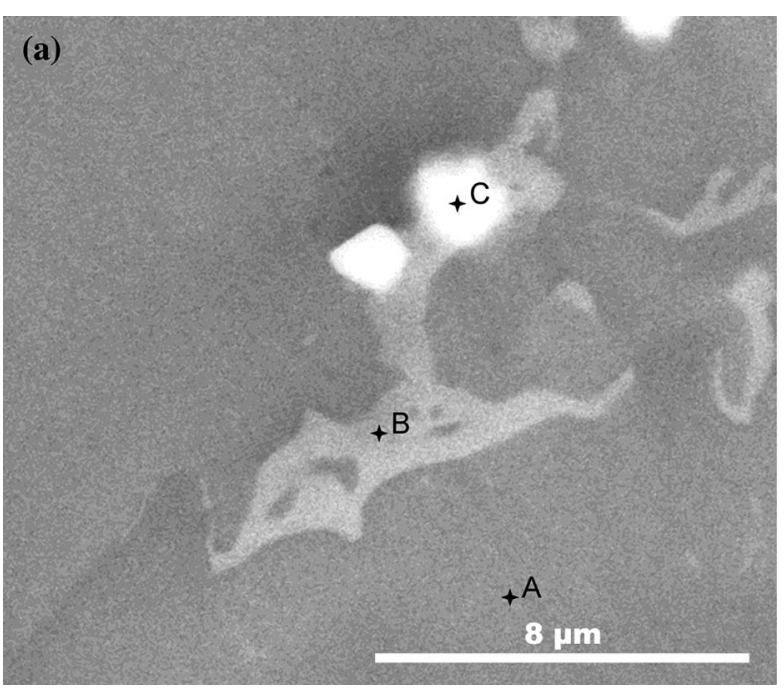

(b)

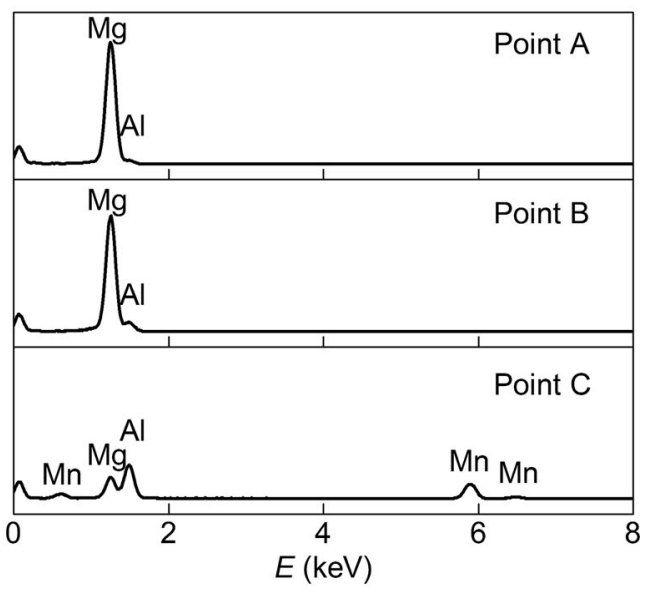

Fig. 4 SEM image a and EDS analysis results $\mathbf{b}$ of the three phases in CNTs/AZ91D composites

Table 2 Area fraction of $\mathrm{Mg}_{17} \mathrm{Al}_{12}$ and $\mathrm{Al}_{8} \mathrm{Mn}_{5}$ in the three kinds of samples

\begin{tabular}{lll}
\hline Materials & $\mathrm{Mg}_{17} \mathrm{Al}_{12}$ & $\mathrm{Al}_{8} \mathrm{Mn}_{5}$ \\
\hline AZ91D Type A & $(6.71 \pm 1.07) \%$ & $(0.16 \pm 0.04) \%$ \\
AZ91D Type B & $(7.58 \pm 0.40) \%$ & $(0.14 \pm 0.02) \%$ \\
0.5 wt\% CNTs/AZ91D & $(7.45 \pm 1.28) \%$ & $(0.13 \pm 0.03) \%$ \\
\hline
\end{tabular}

strong enough to destroy the cylindrical structure of CNTs. And the existence of $9 \mathrm{wt} \% \mathrm{Al}$ does not prevent AZ91D magnesium alloy from working as matrix for CNTs.

\subsection{Tensile Properties}

The tensile properties are presented in Table 3, and representative stress-stain curves (no extensometer was used) are given in Fig. 7. Compared with the AZ91D alloy without ultrasonic (Type A), the yield strength (YS), ultimate tensile strength (UTS), and elongation of the $0.5 \mathrm{wt} \%$ CNTs/AZ91D composite are improved by 18, 6 and 14\%, respectively.
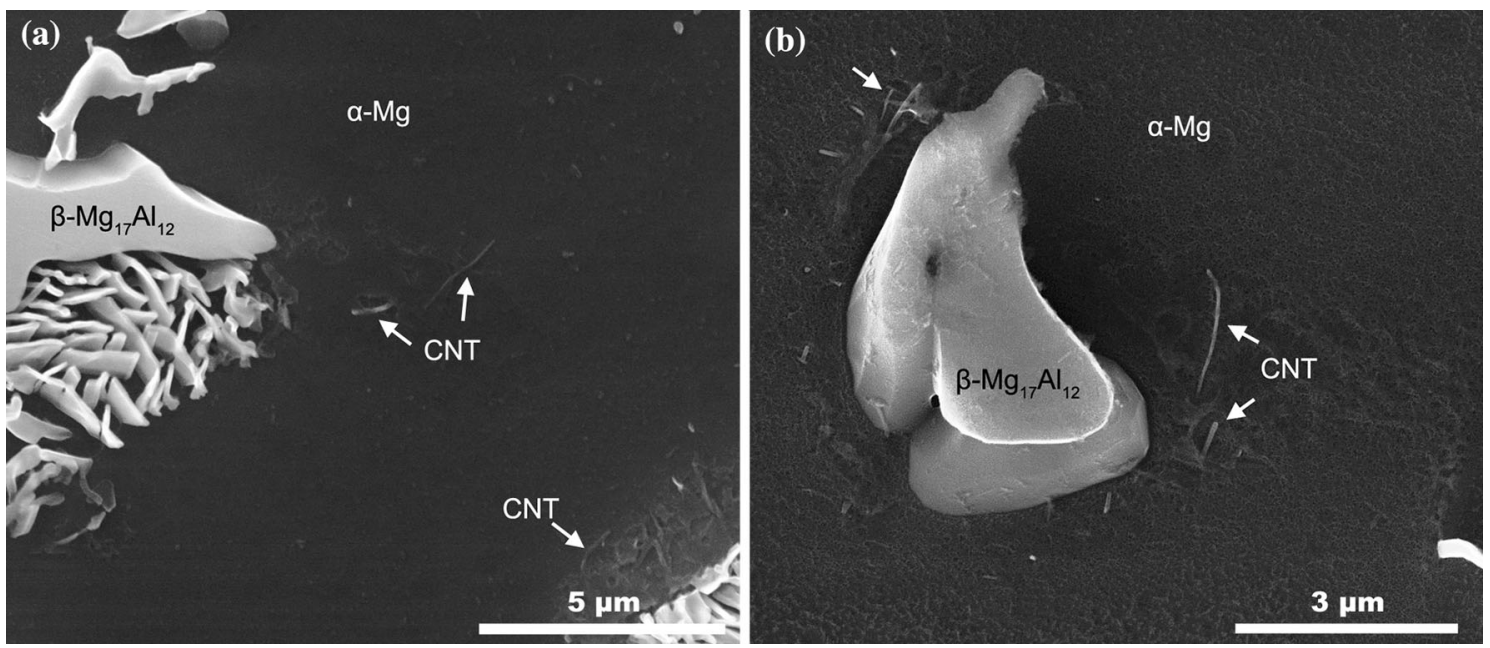

Fig. 5 SEM images showing the distribution of CNTs in AZ91D: a CNTs are located near the eutectic phase at the grain boundary; $\mathbf{b}$ around the $\beta-\mathrm{Mg}_{17} \mathrm{Al}_{12}$ phase 

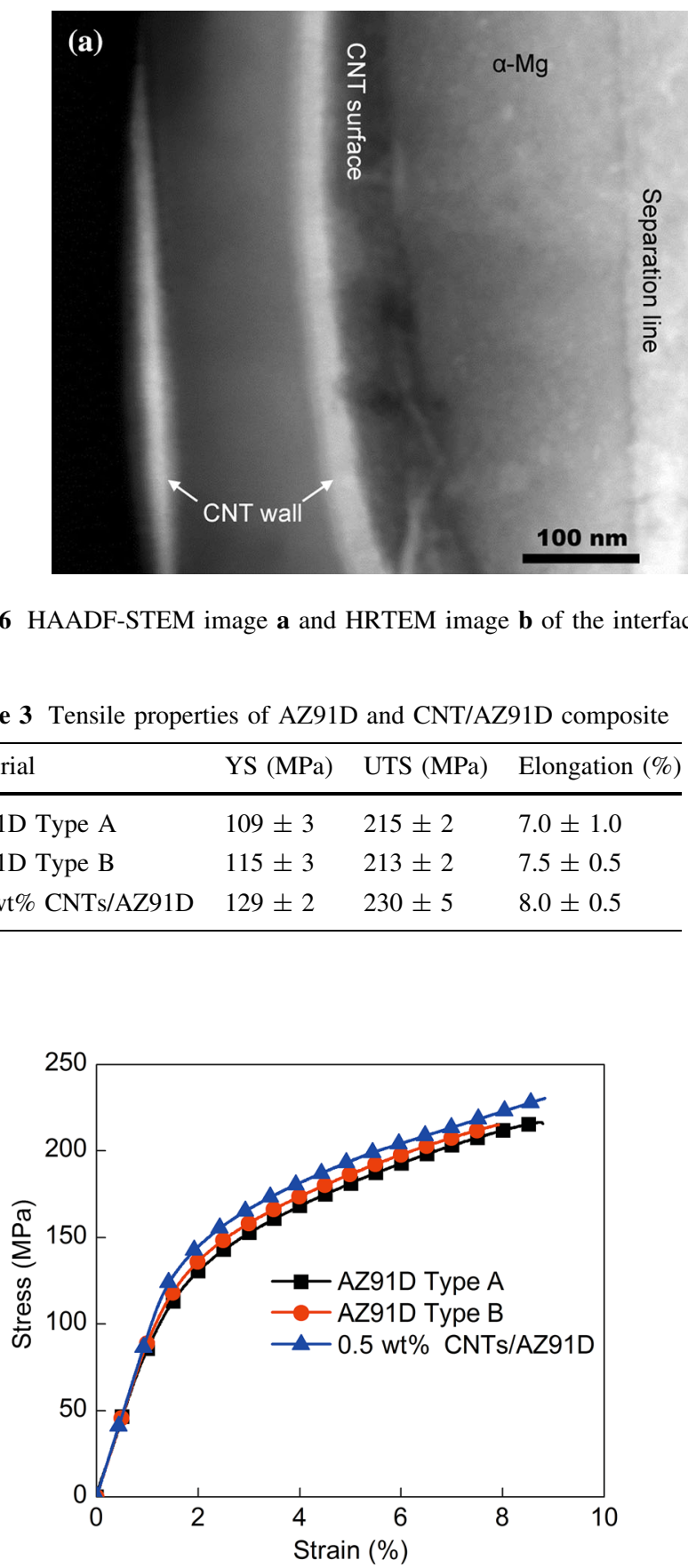

Fig. 7 Representative stress-strain curves of AZ91D and CNTs/ AZ91D composite

\section{Discussion}

\subsection{Grain Refinement Effect of CNTs}

Compared with AZ91D sample, the CNTs/AZ91D composite has a smaller grain size. It seems that the addition of CNTs leads to grain refinement. This result does not consist with the research of Li et al. [21], in which $0.1 \mathrm{wt} \%$ CNTs was added in AZ91D alloy but no obvious grain refinement was found. The main difference of the fabrication process between this work and the work of $\mathrm{Li}$ et al. is that in $\mathrm{Li}$ et al. work, no ultrasonic was used. Actually, ultrasonic process itself causes grain refinement of AZ91D alloy as well [22] and can be also confirmed by the result that the grain size of AZ91D with ultrasonic process (Type B) is smaller than AZ91D without ultrasonic process (Type A). The ultrasonic process in this work was used to further disperse the CNTs in the AZ91D melt. So it can be inferred that the grain refinement effect of CNTs on AZ91D alloy works when CNTs are well dispersed.

The phase component of AZ91D matrix does not change with the addition of CNTs which means the precipitation sequence does not change. For AZ91D alloy, solidification process starts with the precipitation of $\alpha$-Mg phase from liquid phase and end up with eutectic reaction. The existence of massive $\beta-\mathrm{Mg}_{17} \mathrm{Al}_{12}$ phase and lamellar $\beta$ - $\mathrm{Mg}_{17}$ $\mathrm{Al}_{12}$ phase in Fig. 3a indicates that both divorced eutectic reaction and regular eutectic reaction happened during the solidification process. The final grain size is mainly determined by the nucleation of $\alpha-\mathrm{Mg}$ phase. So the influence of CNTs on nucleation of $\alpha-\mathrm{Mg}$ phase should be predominantly considered. Generally, when $0.5 \mathrm{wt} \%$ CNTs are added into the AZ91D melt, it will produce a large quantity of heterogeneous nucleation bases for $\alpha-\mathrm{Mg}$ nuclei which may increase the nucleation rate of AZ91D. But this mechanism is established only on condition of that the interface energy of CNTs $/ \alpha-\mathrm{Mg}$ is low. If not, the high interface energy will prevent the formation of $\alpha-\mathrm{Mg}$ nuclei on CNTs. Unfortunately, no reaction product is found at the CNTs $/ \alpha-\mathrm{Mg}$ interface, and the lattice matching between CNTs and $\alpha-\mathrm{Mg}$ is not good as well. The CNTs used in this work are multiwall carbon nanotubes and have an average outer diameter of $20 \mathrm{~nm}$. Their outer surface can be 
described as graphite layer. As shown in Fig. 8a, the smallest unit of CNTs surface has an axial length of $2.460 \AA$. This axial length is smaller than the smallest interatomic spacing of Mg, $3.209 \AA$ (Fig. 8b). So the only matching may happen between CNTs surface and $\mathrm{Mg}$ (0002) crystal face. But even on such condition, the orientation misfit is $30 \%$ which is too large for a good orientation relationship. Therefore, it is hard for CNTs to work as nucleation base for $\alpha-\mathrm{Mg}$ phase.

This grain refinement may be caused by the inhibition of grain growth by CNTs. As shown in Fig. 5, CNTs are normally observed in the regions near grain boundaries and around intra-crystalline $\beta-\mathrm{Mg}_{17} \mathrm{Al}_{12}$ phase which means CNTs exist at the front of liquid-solid interface during the growth of $\alpha$-Mg phase. So $\alpha$-Mg phase growth in the CNTs/ AZ91D composite needs to push these CNTs away. The existence of these CNTs causes an inhibition of $\alpha-\mathrm{Mg}$ phase growth. The growth of $\alpha-\mathrm{Mg}$ phase is slowed down and the number of crystal nucleus of $\alpha-\mathrm{Mg}$ phase would increase. Since the grain size is mainly determined by the size of $\alpha-\mathrm{Mg}$ phase, the grain would be refined.

Besides, the increasing thermal conductivity caused by the addition of CNTs may be another reason for the grain refinement results. The thermal conductivity of multiwall CNTs is more than $3000 \mathrm{~W} /(\mathrm{mK})$ [23], while the thermal conductivity of AZ91D melt is only about $80 \mathrm{~W} /(\mathrm{mK})$. When weighted average is used to estimate the thermal conductivity of the $0.5 \mathrm{wt} \% \mathrm{CNTs} / \mathrm{AZ} 91 \mathrm{D}$ mixture, the number is about $94.6 \mathrm{~W} /(\mathrm{mK})$. The thermal conductivity of CNTs/AZ91D mixture is higher than the thermal conductivity of AZ91D melt which means the cooling rate of the CNTs/AZ91D mixture is higher than that of AZ91D melt on same pouring condition. So the undercooling of $\alpha-\mathrm{Mg}$ phase in CNTs/AZ91D mixture is larger than the undercooling of $\alpha$-Mg phase in AZ91D, and the nucleation rate of $\alpha-\mathrm{Mg}$ phase in CNTs/AZ91D mixture is higher than it in AZ91D melt. Therefore, an increasing undercooling caused by thermal conductivity improvement involved with addition of CNTs may also play a role in the grain refinement.

\subsection{Strengthening Effect of CNTs}

Taking the high mechanical properties of CNTs into consideration, $18 \%$ increase in yield strength by addition of 0.5 wt\% CNTs is not amazing. When using the Hall-Petch relation, $\sigma_{\mathrm{y}}=\sigma_{0}+k_{\mathrm{y}} \times d^{-1 / 2}$, to fit the data of grain size and yield strength of AZ91D materials, a line representing the as-cast AZ91D alloy in this work is obtained in Fig. 9 (AZ91D Type $\mathrm{C}$ was fabricated on the same condition of Type A but with $100{ }^{\circ} \mathrm{C}$ mold preheating, while Type D was fabricated on the same condition of Type B but with $100{ }^{\circ} \mathrm{C}$ mold preheating). If the data of CNTs/AZ91D composite is also plotted in the same figure, as shown in Fig. 9, the point is only slightly above the Hall-Petch line of as-cast AZ91D alloy. The addition of CNTs does not change the amount and distribution of second phase in AZ91D, so to some extent, the AZ91D matrix in the CNTs/ AZ91D composite is similar to AZ91D materials. If the existence of CNTs were put aside and only the grain refining strengthening were considered, the data point of CNTs/AZ91D composite would obey the Hall-Petch relation of as-cast AZ91D alloy. The fact is the data point of CNTs/AZ91D is only slightly above the Hall-Petch line. In this work, the strengthening effect of CNTs can be divided into two parts: the grain refining strengthening caused by the addition of CNTs and the strengthening effect of CNTs working as reinforcements. And compared with the former one, the strengthening effect of CNTs working as reinforcements does not play a major role. This result consists with those SiCp-reinforced magnesium composites, in which grain refining strengthening also plays an important role $[24,25]$.

This unsatisfactory strengthening effect of CNTs may be caused by the random orientation of CNTs and the poor interface bonding between CNTs and the matrix. The shear lag models [26] used in case of conventional fiber-reinforced composites can also be applied to CNTs composites. The stress is transferred to CNTs $\left(\sigma_{\mathrm{c}}\right)$ via the interface and is related to the shear stress $\left(\tau_{\mathrm{c}}\right)$ between CNTs and $\alpha-\mathrm{Mg}$

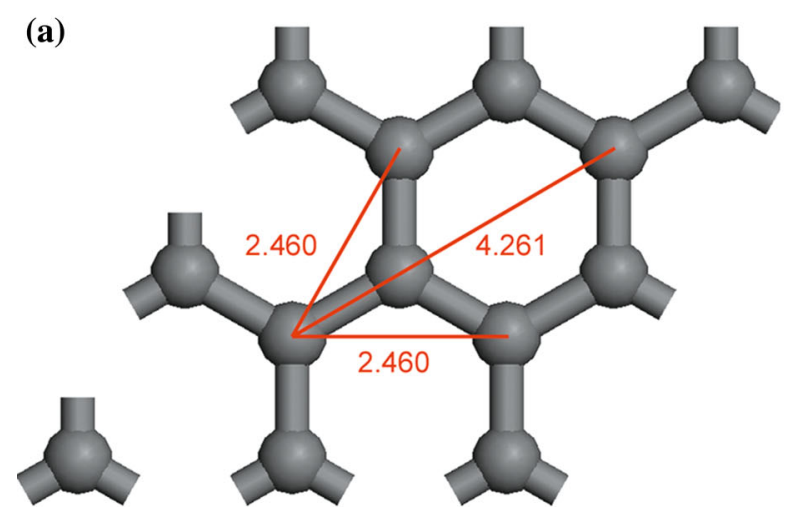

(b)

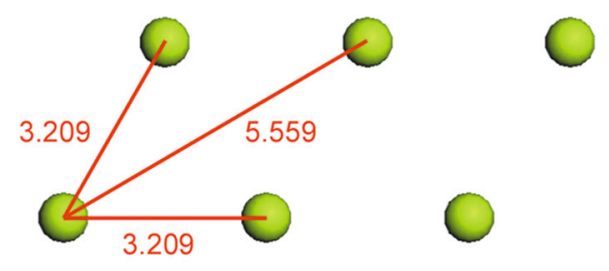

Fig. 8 Atomic arrangements of CNTs surface a and Mg (0002) crystal face b 


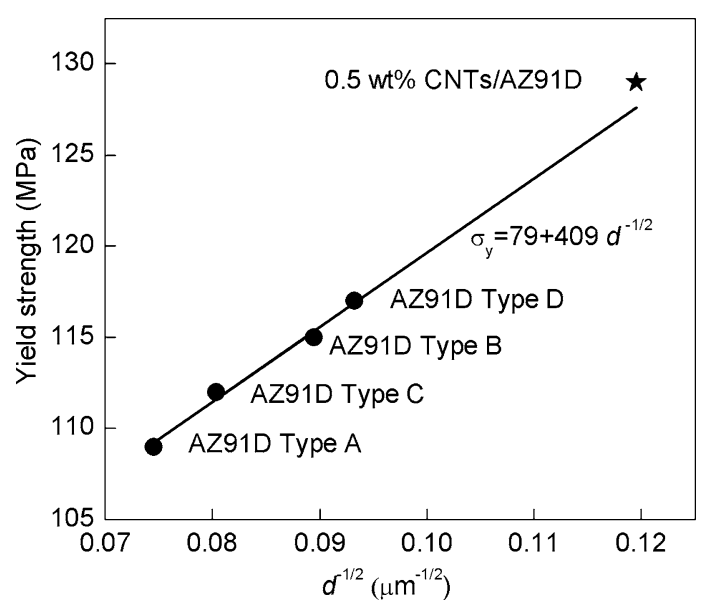

Fig. 9 Hall-Petch relation of AZ91D alloy and the data point of CNTs/AZ91D composite

matrix given by $\sigma_{\mathrm{c}} / 2 \tau_{\mathrm{c}}=l_{\mathrm{c}} / D_{\mathrm{c}}$, where $l_{\mathrm{c}}$ and $D_{\mathrm{c}}$ are the length and diameter of CNTs, respectively [27]. The aspect ratio $\left(l_{\mathrm{c}} / D_{\mathrm{c}}\right)$ of the CNTs used in this work is about 1000 which would, in theory, assist a large load transfer. When the stress transferred to CNTs $\sigma_{\mathrm{c}}$ becomes equal to the fracture strength of CNTs, the shear stress $\tau_{\mathrm{c}}$ is normally lower than the fracture strength of the interface between CNTs and matrix. In this case, CNTs are fractured before the interface and their role as reinforcements is acted, which is shown in Fig. 10, where obvious fracture happens to CNT A and CNT C. But this is an ideal case in which the stress loading axis is parallel to the axis of CNTs and the interface bounding is good enough to transfer the stress. Up to now, no orientation relationship between CNTs and $\alpha$ $\mathrm{Mg}$ matrix has been reported in as-cast CNTs reinforced $\mathrm{Mg}$ or $\mathrm{Mg}$ alloy composites and the orientation of CNTs in composites is random. So in most cases, the axis of CNTs is not parallel to the stress loading axis. The transferred
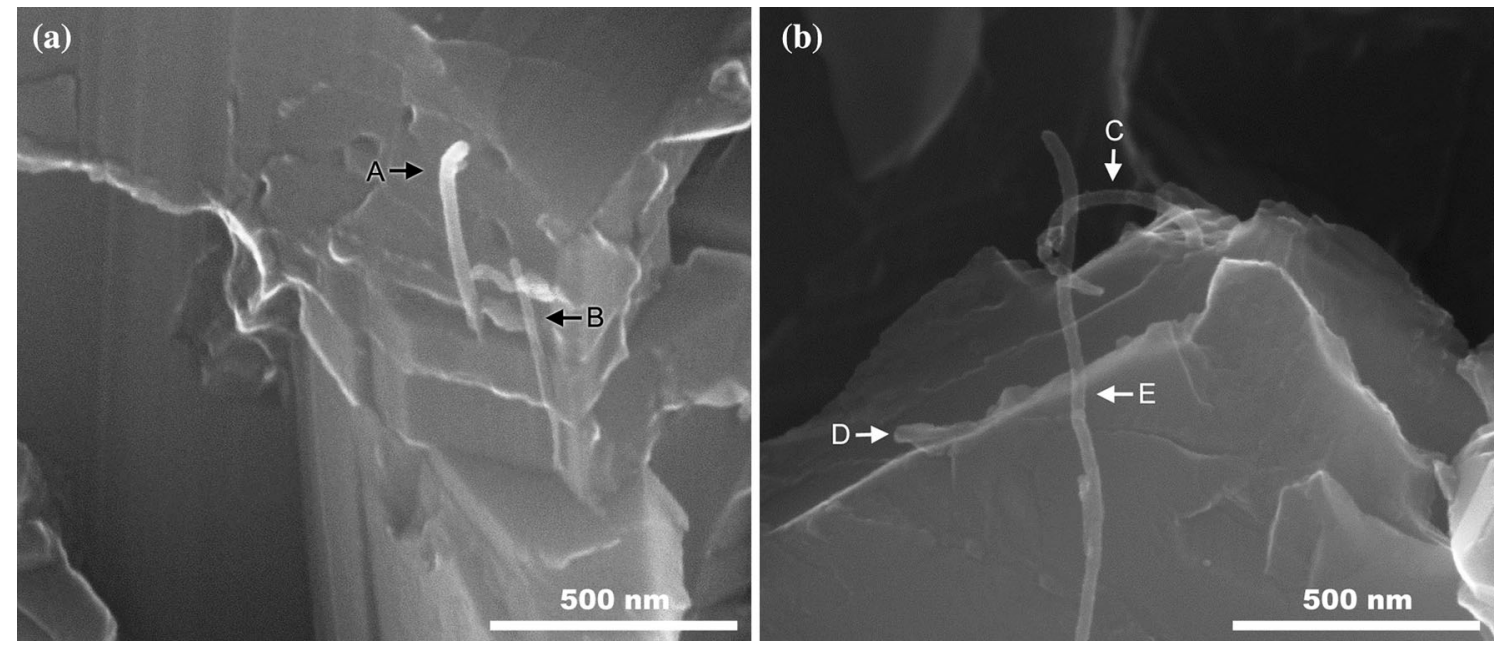

stress $\sigma_{\mathrm{c}}$ is only related to the longitudinal shear stress between CNTs and $\alpha-\mathrm{Mg}$ matrix and the longitudinal shear stress is only part of the whole shear stress which decided by the angle between the stress loading direction and the axis of CNTs. Thus, in most cases, when the interface shear stress is equal to the interface bounding strength, the transferred stress of CNTs is far lower than the strength of CNTs. CNTs are separated from the matrix without fracture and their strengthening effect decreases. To improve this situation, the orientation need to be controlled and the interface bounding should be enhanced. And since the orientation of CNTs in Mg matrix is hard to control, strengthening the interface between CNTs and the matrix seems to be more practical.

\section{Conclusions}

The AZ91D alloy composite reinforced by $0.5 \mathrm{wt} \%$ CNTs was successfully fabricated by ultrasonic processing. The microstructure and mechanical properties of the CNTs/ AZ91D composite were studied, and the following results were obtained:

1. The AZ91D grain can be refined by ultrasonic melt treatment and further refine by the addition of CNTs. The addition of CNTs does not change the phase component of AZ91D alloy. The CNTs were distributed near the grain boundary or around the small $\beta$ $\mathrm{Mg}_{17} \mathrm{Al}_{12}$ phase within the grain. And no obvious reaction product is found at the interface between CNTs and $\alpha-\mathrm{Mg}$. AZ91D magnesium alloy can be used as matrix for CNTs.

2. Compared with monolithic AZ91D alloy, the yield strength, ultimate tensile strength and elongation were improved. Grain refinement is the main reason for this

Fig. 10 Fracture surface of 0.5 wt $\%$ CNTs/AZ91D composite 
progress in mechanical properties. For further improvement, the interface bonding between CNT and the matrix should be strengthened.

Acknowledgments This work was supported by the National Natural Science Foundation of China (No. 51274184). Thanks also go to Qianqian Jin for his help on the TEM work.

\section{References}

[1] R.A. Saravanan, M.K. Surappa, Mater. Sci. Eng. A 276, 108 (2000)

[2] Q.C. Jiang, X.L. Li, H.Y. Wang, Scr. Mater. 48, 713 (2003)

[3] J. Lan, Y. Yang, X.C. Li, Mater. Sci. Eng. A 386, 284 (2004)

[4] H.Y. Wang, Q.C. Jiang, Y. Wang, B.X. Ma, F. Zhao, Mater. Lett. 58, 3509 (2004)

[5] X.Q. Zhang, H.W. Wang, L.H. Liao, X.Y. Teng, N.H. Ma, Mater. Lett. 59, 2105 (2005)

[6] Y. Wang, H.Y. Wang, K. Xiu, H.Y. Wang, Q.C. Jiang, Mater. Lett. 60, 1533 (2006)

[7] S.F. Hassan, A. Gupta, Mater. Sci. Eng. A 392, 163 (2005)

[8] A.K. Chaubey, B.B. Jha, B.K. Mishra, Acta Metall. Sin. (Engl. Lett.) 28, 444 (2015)

[9] B.G. Demczyk, Y.M. Wang, J. Cumings, M. Hetman, W. Han, A. Zettl, R.O. Ritchie, Mater. Sci. Eng., A 334, 173 (2002)

[10] D. Zhou, F. Qiu, H. Wang, Q. Jiang, Acta Metall. Sin. (Engl. Lett.) 27, 798 (2014)

[11] Y. Shimizu, S. Miki, T. Soga, I. Itoh, H. Todoroki, T. Hosono, K. Sakaki, T. Hayashi, Y.A. Kim, M. Endo, S. Morimoto, A. Koide, Scr. Mater. 58, 267 (2008)
[12] K. Kondoh, H. Fukuda, J. Umeda, H. Imai, B. Fugetsu, M. Endo, Mater. Sci. Eng. A 527, 4103 (2010)

[13] H. Fukuda, K. Kondoh, J. Umeda, B. Fugetsu, Compos. Sci. Technol. 71, 705 (2011)

[14] C.S. Goh, J. Wei, L.C. Lee, A. Gupta, Mater. Sci. Eng. A 423, 153 (2006)

[15] M. Paramsothy, X.H. Tan, J. Chan, R. Kwok, M. Gupta, Mater. Des. 45, 15 (2013)

[16] S. Liu, F. Gao, Q. Zhang, X. Zhu, W. Li, Trans. Nonferrous Met. Soc. 20, 1222 (2010)

[17] C.D. Li, X.J. Wang, W.Q. Liu, K. Wu, H.L. Shi, C. Ding, X.S. $\mathrm{Hu}$, M.Y. Zheng, Mater. Sci. Eng. A 597, 264 (2014)

[18] C.D. Li, X.J. Wang, W.Q. Liu, H.L. Shi, C. Ding, X.S. Hu, M.Y. Zheng, K. Wu, Mater. Des. 58, 204 (2014)

[19] H. Shi, X. Wang, C. Li, X. Hu, C. Ding, K. Wu, Y. Huang, Acta Metall. Sin. (Engl. Lett.) 27, 909 (2014)

[20] L. Ci, Z. Ryu, N.Y. Jin-Phillipp, M. Ruehle, Acta Mater. 54, 5367 (2006)

[21] Q. Li, A. Viereckl, C.A. Rottmair, R.F. Singer, Compos. Sci. Technol. 69, 1193 (2009)

[22] X. Liu, Y. Osawa, S. Takamori, T. Mukai, Mater. Sci. Eng. A 487, 120 (2008)

[23] P. Kim, L. Shi, A. Majumdar, P.L. McEuen, Phys. Rev. Lett. 87, 215502 (2001)

[24] M.J. Shen, X.J. Wang, C.D. Li, M.F. Zhang, X.S. Hu, M.Y. Zheng, K. Wu, Mater. Des. 52, 1011 (2013)

[25] M.J. Shen, X.J. Wang, C.D. Li, M.F. Zhang, X.S. Hu, M.Y. Zheng, K. Wu, Mater. Des. 54, 436 (2014)

[26] H.J. Ryu, S.I. Cha, S.H. Hong, J. Mater. Res. 18, 2851 (2003)

[27] S.R. Bakshi, D. Lahiri, A. Agarwal, Int. Mater. Rev. 55, 41 (2010) 